\title{
Research
}

\section{Delivering a national programme of anticipatory care in primary care:}

\author{
a qualitative study
}

\begin{abstract}
Background

Primary prevention often occurs against a background of inequalities in health and health care. Addressing this requires practitioners and systems to acknowledge the contribution of health-related and social determinants and to deal with the lack of interconnectedness between health and social service providers. Recognising this, the Scottish Government has implemented a national programme of anticipatory care targeting individuals aged $45-64$ years living in areas of socioeconomic deprivation and at high risk of cardiovascular disease. This programme is called Keep Well.
\end{abstract}

\section{Aim}

To explore the issues and tensions underpinning the implementation of a national programme of anticipatory care.

\section{Design and setting}

A qualitative study in five Wave 1 Keep Well pilot sites, located in urban areas of Scotland, and involving 79 general practices.

\section{Method}

Annual semi-structured interviews were conducted with 74 key stakeholders operating at national government level, local pilot level and within general practices, resulting in 118 interviews. Interview transcripts were analysed using the framework approach.

\section{Results}

Four underlying tensions were identified. First, those between a patient-focused generalpractice approach versus a population-level health-improvement approach, linking disparate health and social services; secondly, medical approaches versus wider social approaches: thirdly, a population-wide approach versus individual targeting; and finally, reactive versus anticipatory care.

\section{Conclusion}

Implementing an anticipatory care programme to address inequalities in cardiovascular disease identified several tensions, which need to be understood and resolved in order to inform the development of such approaches in general practice and to develop systems that reduce the degree of fragmentation across health and socia services.

\section{Keywords}

anticipatory care; cardiovascular diseases,

inequalities, health; primary prevention. decision making.

\section{INTRODUCTION}

Primary prevention of chronic illness is a key activity in general practice. However, the implementation of primary prevention strategies can result in tensions between population-based public health activity, such as the identification of at-risk populations and screening of those individuals, and the care of individuals at the level of the consultation.' An additional problem is that individuals from lower socioeconomic groups are less likely to participate in preventive programmes, thus exacerbating inequalities in health and healthcare use. ${ }^{2,3}$ While this may be an issue at the public health level, Watt argues that it is not such a problem at the level of primary care, where patients living in areas of deprivation build up longstanding relationships with their practice through repeated access to and use of primary care services.

While prevention programmes may aim to tackle inequalities in health, such approaches often focus on the medical aspects of care, ignoring the fact that health inequalities are clearly intertwined with social determinants of health, including education, housing, employment, and

CA O'Donnell, BSc (Hons), PhD, MPH, professor of primary care research \& development; $\mathbf{F}$ Turner. BSc (Hons), MSc, research assistant; J Clark, BSc (Hons), MSc, research assistant; $\mathbf{Y}$ Wang. MD, MSc, PhD, research assistant, General Practice and Primary Care, Institute of Health and Wellbeing, College of Medical, Veterinary and Life Sciences; M Mackenzie, BA (Hons), MPH, PhD, senior lecturer; M Reid, BA (Hons), MA (Econ), senior research associate, Urban Studies, School of Social and Political Sciences, University of Glasgow, Glasgow. S Sridharan, MS, PhD associate professor and director, The Evaluation Centre for Complex Health Interventions, The Keenan Research Centre, Li Ka Shing Knowledge Institute, St Michael's Hospital, Toronto and Health Policy, Management and Evaluation, University of Toronto, Ontario. S Platt, BSc (Hons), MSc, PhD, Professor of Health Policy Research, Centre for income..$^{4-6}$ As a result, some argue that health services must be redesigned to address both sets of determinants. ${ }^{2,6-8}$ This approach, known as health improvement, takes a population perspective and seeks to integrate different services, including health care, social care and the voluntary sector.? All too often, however, systems are fragmented, leaving patients and practitioners unsure about how to access help to deal with pressing non-medical problems. ${ }^{10}$

Such issues have a particular resonance in Scotland, where inequalities in health and healthcare use are particularly entrenched. ${ }^{11}$ The Scottish Government has outlined its commitment to developing a health service that tackles inequalities in health, addressing both health and social determinants, and to delivering a health service that moves away from a reactive, episodic model of care, where the patient is a passive recipient, to a system that anticipates health needs before they arise and that delivers continuous, integrated, preventive care with the patient as partner. ${ }^{12,13}$ Such a model of care has been termed anticipatory care. This is not, however, a new concept.
Population Health Sciences, School of Clinical Sciences and Community Health, University of Edinburgh, Edinburgh.

\section{Address for correspondence}

Catherine A O'Donnell, General Practice and Primary Care, Institute of Health and Wellbeing, College of Medical, Veterinary and Life Sciences, University of Glasgow, 1 Horselethill Road, Glasgow G12 9LX

E-mail: Kate.O'Donnellaglasgow.ac.uk Submitted: 12 July 2011; Editor's response: 7 September 2011; final acceptance: 15 November 2011.

British Journal of General Practice

This is the full-length article lpublished online 26 Mar 2012) of an abridged version published in print. Cite this article as: Br J Gen Pract 2012; DOI: 10.3399/bjgp12X636137. 


\begin{abstract}
How this fits in
Primary prevention of chronic disease is an important activity in primary care, but inequalities in health and health care use means that such programmes need to address both health-related and social determinants of health. In Scotland, the Government have implemented a programme of anticipatory care to reduce inequalities in cardiovascular disease, drawing on the work of Julian Tudor-Hart. This paper reports on the tensions which underpin such a programme, in trying to integrate population-level health improvement with general practice-based, individual care.
\end{abstract}

Anticipatory care, as an approach, was pioneered in the 1960s by Van den Dool in The Netherlands and Julian Tudor Hart in Wales. Both developed approaches that involved the identification of patients at high risk, for example, of particular diseases or clinical conditions, by reviewing medical records or by addressing such needs with patients opportunistically during routine consultations or other patient-instigated contacts with the practice. ${ }^{14,15}$ Tudor Hart's approach led to improvements in a number of clinical measures, including smoking rates in men and levels of hypertension. There was also a $28 \%$ reduction in coronary heart disease (CHD)-related mortality over a 25-year period in his practice, compared with a similar, neighbouring practice, although he and his team were careful not to attribute this reduction in mortality solely to their approach of case finding and audit. 16,17 Integral to success was seeing patients as 'co-producers' of their health and it is this, coupled with a practitioner's knowledge of their patients' health, personal and social situations, that, for some, remain central to the approach of anticipatory care. ${ }^{18-20}$

In a fragmented healthcare system, this approach may be difficult to replicate..$^{10}$ It is, however, possible to identify the active ingredients of an anticipatory care programme, regardless of setting (Box 1) These 'active ingredients' combine elements of the practitioner-patient relationship exemplified in general practice with population approaches from public health. Recently, the Scottish Government has established Keep Well, a national programme of anticipatory care targeting deprived populations at risk of developing cardiovascular disease (CVD), which brings together a number of the active ingredients important to anticipatory care. The key features of the programme and its evaluation are described in Box 2. However, while the implementation of Keep Well was intended to address some of the systems failings that fragmentation can cause, it has also exemplified the tensions that such an approach can create. This paper reports a qualitative exploration of these issues through interviews with stakeholders working at both strategic and operational levels of Keep Well, including GPs, and draws lessons for the wider implementation of programmes of national screening in primary care that are designed to reduce inequalities in health.

\section{METHOD}

Study design and setting

A qualitative approach was adopted; semistructured interviews were conducted with staff purposively selected to provide key perspectives on the implementation of Keep Well. These were carried out in the five Wave 1 pilot sites, all of which were located in the predominately urban central area of Scotland.

\section{Sample and data collection}

Interviewees included policy makers operating within Scottish Government; strategic decision makers and project managers within local pilot programmes; and primary care professionals delivering Keep Well in general practices. Interviewees were identified on the basis of the team's knowledge of key stakeholders, both nationally and in each pilot site, and through discussion with the programme managers. A handful of potential interviewees declined to take part, generally due to lack of time, but in most cases suggested an alternative interviewee. Several interviewees were interviewed annually over the 3 years of the project.

The interview schedules were framed around the aim of understanding the theory, practice and implementation of Keep Well. In the first year of Keep Well, the schedule focused on understanding why the project had emerged at a national level and its implementation. In year 2, the focus was on key changes in approach, progress and general learning. The final round of interviews had a particular emphasis on the sustainability of Keep Well. (Copies of the interviews are available on request to the corresponding author.) Informed consent was obtained from all interviewees and the interviews transcribed in full.

Interviews were carried out by members of the team, all of whom are experienced in conducting research in general practice or primary care settings. Interviews generally lasted between 50 and 75 minutes. 


\section{Box 2. Summary of the Keep Well programme and its evaluation. ${ }^{23}$}

\section{Aim of Keep Well}

The aim of Keep Well is to increase the rate of health improvement in CVD for those living in the most socioeconomically deprived communities of Scotland, through early intervention with those at high risk of $\mathrm{CHD}$ and diabetes.

\section{What is it?}

A population-based health-improvement programme delivered thorough the operational system of general practice.

\section{Target population}

The programme targets geographic communities with high levels of multiple deprivation and, within this, patients registered with general practices and aged between 45 and 64 years. The first wave (2006-2010) targeted communities in five areas of central Scotland, with a total target population of 87440 . Funding was subsequently extended and these pilots continue to target and recruit patients.

\section{Key features of the Keep Well programme}

- Those at risk of preventable serious ill-health (including those with undetected chronic disease) are identified.

- These individuals are invited to attend a health check conducted by a member of the practice team, usually the practice nurse.

- Evidence-based interventions and services are then offered, as appropriate. These may be located within primary care or hospital settings, or outside the NHS.

- Interventions can be medical (for example, statin prescribing); health-related behavioural change (for example, smoking cessation, alcohol counselling); or social (for example, literacy support, welfare benefits advicel.

- Monitoring and follow-up are provided, as required.

\section{Roll-out}

Three subsequent waves of Keep Well have been rolled out in new areas. Anticipatory care approaches modelled on Keep Well are being tested in new settings (for example, community pharmacy) and populations (for example, prisons and black and ethnic minority communities) and in remote and rural areas of Scotland.

\section{Evaluation ${ }^{24,25}$}

The evaluation was conducted in two phases, from 2007 to 2010

- Phase 1: a theories of change approach ${ }^{26}$ was used to explicate the rationale for the programme and to track and text change over time. This phase incorporated both qualitative data collection and quantitative analyses of routinely available data.

- Phase 2: informed by the principles of realistic evaluation, ${ }^{27}$ case studies were used to further explore and understand the impact of contextual variations, in particular practice socioeconomic deprivation, and different approaches to reach and engagement. undertaken by the team, with a considerable amount of cross-checking. A key theme was responders' understanding of Keep Well. Subthemes included: the origins of Keep Well; understanding of key concepts and definitions; and the rationale underpinning the development of the model. The resulting charts associated with this theme were inductively explored for the purpose of this paper

Quotations were selected to illustrate pertinent points. To maintain anonymity, codes were used for each interviewee national interviewees $(\mathrm{N})$; pilot level interviewees by (A) to (D) to distinguish between the four geographical areas in which pilot sites were located ltwo pilots were located within the same geographical region and treated as a single site); and by the year of interview (indicated as round 1, 2, or 3).

\section{RESULTS}

Seventy-four individuals were interviewed over the 3 years, generating a total of 118 interviews. Of these, 26 were national-level interviews, 28 were undertaken in pilot site $A_{;} 22$ in pilot site $B ; 18$ in pilot site $C$; and 24 in pilot site $D$ (Table 1). A similar range of interviews were conducted in each pilot site, including those charged with implementing the programme, those with a healthimprovement dimension to their work, and those delivering the programme in practices, including GPs and practice nurses.

\section{Rationale for Keep Well}

The policy origins of Keep Well were most apparent to national interviewees. All discussed Julian Tudor Hart and several referred to the Scottish Government's health policy document Delivering for Health, ${ }^{12}$ which outlined plans for a programme of anticipatory care.

Political imperatives underpinned aspects of the approach adopted. The Minister of Health wanted to ensure that Keep Well was located in, and delivered by, general practice, in order to more explicitly

\section{Table 1. Geographical and temporal spread of interviews}

\begin{tabular}{lccccc} 
& $\begin{array}{c}\text { Interviews } \\
\text { round 1 } \\
(\mathbf{2 0 0 7 )}\end{array}$ & $\begin{array}{c}\text { Interviews } \\
\text { round 2 } \\
(\mathbf{2 0 0 8 )}\end{array}$ & $\begin{array}{c}\text { Interviews } \\
\text { round 2 } \\
\text { (2009) }\end{array}$ & $\begin{array}{c}\text { Total number } \\
\text { of interviews }\end{array}$ & $\begin{array}{c}\text { Total number } \\
\text { of participants }\end{array}$ \\
\hline National & 13 & 6 & 7 & 26 & 17 \\
\hline Area A (pilots 1 and 2) & 15 & 8 & 5 & 28 & 18 \\
\hline Area B & 10 & 7 & 5 & 22 & 12 \\
\hline Area C & 8 & 6 & 4 & 18 & 11 \\
\hline Area D & 11 & 7 & 6 & 24 & 15 \\
\hline Total & 57 & 34 & 27 & 118 & 73 \\
\hline
\end{tabular}


involve it in tackling health inequalities. The choice of target age group and the disease focus were also pre-specified, although some interviewees suggested that, by middle age, unhealthy behaviours were already entrenched. The focus on heart disease was, however, accepted by all because the risk factors for CVD contributed to other diseases as well.

Analysis identified four underlying tensions in the delivery of an anticipatory care approach through general practice:

- general practice versus healthimprovement approaches;

- medical approaches versus wider social approaches;

- population-wide approach versus individual targeting; and

- reactive versus anticipatory care.

\section{General practice versus health- improvement approaches}

There was a tension between two visions of Keep Well: as an NHS-centred model delivered through general practice, or as a wider, health-improvement programme linking disparate health and social care providers. National interviewees acknowledged that a model developed in the 1960s was not entirely transferable to urban practices in the 21 st century. However, general practice was viewed as the logical place to site Keep Well, as it could build on the existing rapport and relationship between GPs and their patients:

'The GP relationship was seen as being at the heart of it and just freeing up more time for GPs to spend with the patients that most needed it was always at the heart of the discussions we had.' (N003, round 1)

However, one interviewee was clear that the model adopted was not integrated into general practice in the way that Tudor Hart had worked:

'[The model was] bolted onto the outside of general practice rather than nested in the heart of it.' (N010, round 1)

While this view was not held by all, it encapsulated the tension raised by having health checks delivered through a specifically arranged, much longer consultation with a member of the practice team (usually a practice nurse) rather than embedded within routine consultations instigated by the patient. This interviewee suggested that such an approach would reach only those who usually responded to such invitations, potentially steepening the inequalities gradient.

For interviewees working at the pilot level, particularly those with a public-health or health-improvement background, the distinction between general practice and health improvement was less clear. In some pilot areas, Keep Well built on prior work linking general practice to wider healthimprovement programmes, located both within and outside the NHS:

'We have been doing a lot of work over the years in the more deprived communities in [pilot area B]. Keep Well didn't happen in a vacuum ... there's a lot of regeneration work going on ... there's a lot of work going on to support communities in deprived areas to create employment, improve the environment.' (B011, round 1)

By year 3, it was recognised that the wider health-improvement services offered to patients depended very much on what had developed locally in a pilot area, prior to Keep Well. This was acknowledged as a potential problem as Keep Well developed and moved into other geographic areas, where such services might be less well developed:

... the programme, when it comes to referral onto other services, it really depends on what's there already, what's been invested previous to the programme and certainly when we move into remote and rural areas, some services just don't exist and if they do, it's significant travel times ...' (N002, round 3)

For interviewees at the pilot and practice level, however, the principal purposes of Keep Well were to reduce inequalities, increase capacity in primary care, and assist in service reorganisation, to help those from the most deprived areas make more effective use of primary care services. This raised other tensions, which are discussed in turn.

\section{Medical approaches versus wider social approaches}

Most participants recognised that, if Keep Well is to meet its stated aim of reducing health inequalities, it has to address both health-related and social determinants. However, delivery through general practice led to a more medical focus than some might have wished:

.... for the first time they're really bringing 
together the community development and the medical approach and I think that is hugely complex and I think that these two tensions could eventually really complement each other. But I think we're a long way from that. Because I think as well, you know, I feel that I'm coming with my community education hat on to this role obviously and I feel that we're not taken as seriously as the medical approaches within this project.' (C005, round 1)

While addressing social determinants was an aim of Keep Well, this required partnerships with organisations outside the NHS. The tensions and challenges of combining this with a medical approach were acknowledged:

So I think, you know, some of the socioeconomic elements that will spill out of this [Keep Well] need to be addressed as well, and I think that's why we've been keen to try and work in partnership with, not only the local authority, but some of the voluntary sector ... it is about, you know, a holistic partnership approach to trying to, not only lift the physical health of the population, but lift the mental health, the self-esteem, the employment, the employability, and you know, just generally raise the, the standards across all aspects of life, for people.' (B007, round 1)

One reason, offered at a national level, for this reliance on the medical model was the need to deliver tangible benefits in a short time period. One national interviewee offered a cogent explanation:

'... it's not difficult to do the right things, but it's difficult to capture the evidence of effectiveness of those right things, within the political cycle. If you are only in power for 5 years, something that delivers effect in 40 years is not very attractive... Well you want to put it into something that has proven effectiveness, that can be delivered by your department and where the levers are at your hand and you think, well, CVD hits the buttons because you can target people at an age where they are likely to become ill if they don't act and as well as the unreliable things of behaviour change, you get [unclear] medication - give them all the ACE [angiotensin-converting enzyme] inhibitors and the statins and the aspirin and the beta-blockers and you will increase their life expectancy. So, it's a sure-fire bang for bucks.' (N006, round 1)

Thus, Keep Well offered an opportunity to test primary care's contribution to a social model, where a wide range of activities was being used to change people's lives. General practice attracted patients into the system but, thereafter, patients could be directed towards a wider, more holistic range of services. This led to tensions later, as the focus of the programme broadened to address these wider determinants of health that had a less well-developed evidence base. For one interviewee, this reduced the possibility of demonstrating the effectiveness of an anticipatory care approach:

... there remains tension in Keep Well and I think that the, the original perception ... was very narrow and medical and perhaps wisely so. It wasn't attempting to solve all the world's problems and it was always more likely to succeed because of its limited aims, whereas I think Keep Well has developed and developed and is now probably wildly ambitious, attempting to address all the social problems that people are facing and the more you try to do the less you are likely to succeed ...' (N001, round 3)

By year 3, this also led to the realisation that there was a lack of boundaries around Keep Well's responsibility to patients once they had been referred on to other services.

\section{Population level versus individual targeting}

The policy premise for Keep Well was that of reducing the gap in CVD-related morbidity and mortality between the most affluent and the most deprived. Interviewees were unclear, however, whether Keep Well was trying to reduce this gap or raise the health of the most deprived to an undefined population norm. They were also unclear as to whether Keep Well should target only the most socioeconomically-deprived individuals within an area, or all individuals living within a pre-defined area of deprivation, regardless of personal-level socioeconomic status. This resulted in the delivery of different models at pilot level. Three sites targeted all patients within the 45-64 year age band, regardless of whether the patient lived in a deprived postcode area or not; one site targeted only registered patients in the correct age group and living in the most deprived postcode areas; and one area bypassed identifying patients through practices completely and, instead, used a community-based approach.

For some, there was no tension between population and individual targeting: 
'I think you need both ... particularly in areas such as [pilot area A] ... we've got quite a high percentage of people who don't engage with services. We've got a high percentage of individuals and families and groups who are vulnerable, however you want to define that ... But, as I say, we know that many people don't [access services] ... for various reasons so the value of this and the value of targeting it in an area such as [pilot area A] and the specific client group is that we can begin to look at different ways of service delivery and the barriers to people accessing services.' (A008, round 1)

A recognised unintended consequence of targeting all patients registered with a general practice, regardless of individual socioeconomic status, was the inclusion of patients who had little or no need for a Keep Well intervention. There was some reflection in the year 3 interviews about the number of people screened who may not have any identifiable risks. However, this was viewed as worthwhile, if it allowed Keep Well to target those who were at risk but who had not acknowledged that risk, often because of other, more pressing, life needs and circumstances:

Well the difference is, I used the term the unworried unwell and we don't have any other programmes which are trying to help that group. Everything else is either targeting the worried well or the worried unwell but we don't have anything that is targeting people who are not good, who have all sorts of health problems - either now or storing them up for the future - but it's certainly not high on their [agenda] Nobody's ever completely unworried but it's just not something that they're concerned enough about to do something about it ... It's not because they're stupid or irresponsible or whatever, because often they're accused of that, but there are other things that are more important, that are just a more, bigger, day-to-day priority.' (D004, round 1)

\section{Reactive versus anticipatory care}

The underpinning rationale of Keep Well, that of moving from reactive care to an anticipatory form of care, was welcomed by all, particularly those in general practices:

'It tends to be a luxury for the NHS because we're caught up in dealing with the burden of reactive patients that we see coming through the door.' (B008, round 1)

However, as alluded to above, there was a recognition that patients themselves may not be ready for such an approach, with health-related matters receiving a lower priority in their lives due to complex social needs. Although the focus on medical aspects of care was problematic in this context, Keep Well was an important opportunity:

'You have all of the elements in place for providing not just reactive care but a much more outward-looking, public-health sort of care for a population, which is what I hope primary care teams may evolve into. And if we can use this to support that, well, then good. If we don't use this, that's an opportunity lost.' (D003, round 1)

By year 3, there was also recognition nationally that, in order to see long-term health improvements, there would have to be long-term support for patients, after the Keep Well health check:

... less emphasis has been placed on how do we ensure individuals attend services, uptake treatment and maintain that for the length of time that's required to see the changes happening ...' (NOO2, round 3)

However, while welcomed, there was no shared understanding or definition of anticipatory care:

'I mean I suppose we're, we're still struggling with what we truly are meaning by anticipatory care, and it gets bandied about without people necessarily being concise about what we do mean by that. (N013, round 1)

Phrases used to describe anticipatory care included: 'reduce inevitability [of illness]' (N002); 'anticipating a worse event at a later point' (N003); 'prevent ill-health through early detection' (N004); and 'intervene to alter risk factors' (N018). Interviewees saw it as more than primary prevention, however, and highlighted the importance of additional elements, such as patient engagement, the proactive nature of the encounter with the patient, and the relationship between the patient and the healthcare professional. There was also debate about whether anticipatory care encompassed secondary prevention as well as primary prevention.

'I think it's helpful to think of anticipatory care as meaning both inequalities targeted high risk primary prevention and cardiac rehab ... but the intensity and skills required at those different levels will obviously be appropriate to the severity of the 
circumstances ...' (N006, round 3)

Thus, Keep Well was increasingly seen as being part of a continuum of preventive care.

\section{DISCUSSION}

\section{Summary}

This paper has reported on the implementation of a national programme, designed to reduce inequalities in CVD by addressing both health-related and social determinants of ill-health and located in general practice. Key components of an anticipatory care approach were applied, 20,21 including: targeting individuals in deprived areas at risk of developing CVD; building on the relationship between patients and general practices; and the identification of health needs and problems before they become manifest.

Although based on the work of Tudor Hart, this approach used a dedicated health check to screen patients, rather than doing this as part of a routine patient-led consultation. The principal practitioner involved was rarely the GP, but generally another member of the primary healthcare team, usually a practice nurse. Finally, there was an explicit recognition of the role of social determinants, as well as healthrelated clinical and behavioural risk factors, in perpetuating health inequalities. To address these social determinants, Keep Well tried to strengthen the links between primary care and other, community-based services, such as literacy services or benefits advice, reducing system fragmentation for patients. This did lead to tensions, however, and was dependent on the pre-existence of such communitybased services and practices' knowledge of them. These findings were fed back to the national programme, as part of an iterative approach to the evaluation, and have helped to inform the ongoing development of Keep Well.

\section{Strengths and limitations}

This study has afforded the opportunity to explore the implementation of a national programme of anticipatory care as it developed over a period of 3 years, through the use of repeat interviews with key stakeholders working at the level of national policy making, as well as those charged with implementing the programme in each of the pilot sites and those delivering the service to patients. This work was underpinned by an approach called 'theories of change'. ${ }^{26}$ This approach gives researchers the opportunity to explore, with those being interviewed, their views about the underlying rationale of a programme; what it is intended to achieve at its outset; how its goals will be met; and whether these are met in reality and, if not, why not. This provided a useful theoretical, methodological and analytical framework for a longitudinal study.

However, the study also had limitations. In particular, interviewees spoke most about their views of anticipatory care in the first and third round of interviews, but not in the second round, probably as the interviews conducted then focused on strategies to promote reach and engagement with patients.

\section{Comparison with existing literature}

Keep Well focused on the identification and treatment of patients at risk of developing CVD. This was unsurprising, given the global burden of disease that CVD represents. ${ }^{29-31}$ However, many practitioners felt that the focus on patients aged 45-64 years was too late and that activity should focus on younger patients, especially in deprived areas, where las already commented on) poorer health and health-related behaviours are already entrenched.'

Keep Well was designed to address disparities in CVD, ${ }^{12}$ by reducing the gap in health between the most deprived and more affluent populations. However, at least two approaches developed across the pilot sites: some practices focused only on the most deprived patients within their population, while others encouraged all patients within the eligible age range to attend for a health check. This was often a pragmatic decision, depending on the level of deprivation in the practice population, 32 but also highlights the difficulty of operationalising approaches to reduce inequalities in a complex system such as general practice, unless there is an explicit articulation of the rationale underpinning the programme. Keep Well also targeted patients and invited them in for a dedicated health check, unlike the undifferentiated approach of Tudor Hart, ${ }^{16}$ who dealt with issues as and when the patient presented them. Such an approach, which of course did not result in comprehensive coverage, may thus have the unintended consequence of increasing inequalities, if those who are least at risk attended for a health check. ${ }^{32}$ For this reason, Keep Well went on to explore other methods of contacting patients, including the use of community venues and outreach workers. ${ }^{33}$ However, it also confirms the validity of the contention that both population and targeted 
approaches can coexist within a practice. 5,34 $^{2}$

\section{Implications for practice and research}

The key practitioner in many practices was not the GP, but the practice nurse who conducted the health checks and referred patients onto other practitioners, including the GP, or other services as appropriate. This mirrors the increasingly important role that practice nurses play, particularly in the management of chronic diseases within practices. ${ }^{35-37}$

It has been suggested that a health check approach is simplistic and flawed, in relation to the needs of patients with complex needs' as it does not address the long-term needs of patients. ${ }^{1}$ The present study found that Keep Well was developing a system-wide approach, which was attempting to integrate approaches addressing both the health and social determinants of inequalities. However, the extent to which health services, such as general practice and health promotion, integrate and collaborate with non-health services, such as employment advice and literacy services, was dependent on previous relationships and collaborations within a geographical area. There is also a need to make clear the boundaries of a service such as Keep Well, for example when it passes on responsibility for patients to other services. The more rapid improvements in patient and population health possible with medical interventions should also be acknowledged. Finally, the workload and resource implications of such a programme of work cannot be underestimated; the continued development and embedding of such an approach in primary care will require health services to address the resources required to do that.

This paper reports entirely on the views of professionals charged with the strategic and operational delivery of Keep Well. However, patients may also need to be supported to believe that they are eligible for such preventive approaches to health. ${ }^{3}$ These issues are also likely to be important for other programmes of high-risk primary prevention, for example the Department of Health's Putting Prevention First in England, which plans to offer vascular health check and risk assessment to all adults aged 40-74 years in England, ${ }^{38}$ or approaches to prevention described in the US Government's programme Healthy People 2010.4 Based on experiences in Scotland, the authors would suggest that any such programme should consider and clarify whether the approach to be adopted is one of primary prevention for an entire population or a targeted intervention directed at high-risk individuals within geographical areas. If the latter, they would recommend a community-wide advertising strategy that engages with the target population to legitimise their right to attend and explains to those not eligible why they are not eligible. ${ }^{39}$ General-practice- and public-health-based approaches, such as local health improvement teams, also need to improve understanding of each other's roles and agree on areas of joint working. Finally, the potential risks of exacerbating. rather than diminishing, health inequalities should be acknowledged. 


\section{REFERENCES}

1. Watt G. Anticipatory care in very deprived areas. Br J Gen Pract 2011; 61(584): 228.

2. Bierman AS, Dunn JR. Swimming upstream. Access, health outcomes. and the social determinants of health. J Gen Intern Med 2006; 21(1): 99-100.

3. Dixon-Woods M, Cavers D, Agarwal S, et al. Conducting a critical interpretive synthesis of the literature on access to healthcare by vulnerable groups. BMC Med Res Methodol 2006; 6(1): 35.

4. US Department of Health and Human Services. Healthy people 2010. Understanding and improving health (2nd edn). Washington DC: US Government Printing Office, 2000.

5. Whitehead M, Dahlgren G. Concepts and principles for tackling social inequities in health: Levelling up. Part 1. Copenhagen: WHO Regional Office for Europe, 2007.

6. Marmot M. Fair society, healthy lives: The Marmot Review. Strategic review of health inequalities in England post-2010. London: University College London, 2010

7. Baum FE, Begin M, Houweling TAJ, Taylor S. Changes not for the fainthearted: Reorienting health care systems toward health equity through action on the social determinants of health. Am J Public Health 2009; 99(11): 1967-1974

8. Baum FE. More than the tip of the iceberg: health policies and research that go below the surface. J Epidemiol Community Health 2009; 63(12): 957.

9. Davies L. The new public health strategy for England. BMJ 2010 Dec 8; 341: c7049.

10. Stange KC. The problem of fragmentation and the need for integrative solutions. Ann Fam Med 2009; 7(2): 100-103.

11. The Scottish Government. Equally well. Report of the Ministerial Task Force on Health Inequalities. Edinburgh: The Scottish Government, 2008.

12. Scottish Executive. Delivering for health. Edinburgh: Scottish Executive, 2005.

13. NHS Scotland. Better health, better care action plan. Edinburgh: Scottish Government, 2007

14. Van den Dool C. Allgemeinmedizin International 1973; 3: 100

15. Tudor Hart J. The marriage of primary care and epidemiology. J R Coll Physicians Lond 1974; 8(4): 299-314.

16. Tudor Hart J. Coronary heart disease prevention in primary care: Seven lessons from three decades. Fam Pract 1990; 7(4): 288-294.

17. Tudor Hart J, Thomas C, Gibbons B, et al. Twenty five years of case finding and audit in a socially deprived community. BMJ 1991; 302(6791): 1509-1513.

18. Crebolder HFJM, van der Horst FG. Anticipatory care and the role of Dutch general practice in health promotion - a critical reflection. Patient Educ Couns 1996; 28(1): $51-55$.

19. Tudor Hart J. Further from Washington: can Celtic UK renew the NHS? Lancet 2004; 364(9434): 633-635.

20. Watt G, O'Donnell C, Sridharan S. Building on Julian Tudor Hart's example of anticipatory care. Prim Health Care Res Dev 2011; 12(1): 3-10.

21. Sridharan S, Gnich W, Hume M, MacDougall I. Towards a checklist of questions for planning anticipatory care initiatives: using the lessons learned from Have a Heart Paisley Phase II. Edinburgh: University of Edinburgh, Research Unit in Health, Behaviour and Change, 2007.

22. Sridharan S, Gnich W, Moffat V, et al. Independent evaluation of Have a Heart
Paisley Phase 2. Evaluation of the Phase 2 primary prevention. Edinburgh: University of Edinburgh, Research Unit in Health, Behaviour and Change, 2008 .

23. Mackenzie M, O'Donnell C, Halliday E, et al. Do health improvement programmes fit with MRC guidance on evaluating complex interventions? BMJ 2010; 340: c185.

24. O'Donnell C, Mackenzie M, Platt S, et al. National evaluation of Keep Well interim report: national level. Edinburgh: NHS Health Scotland, 2008.

25. O'Donnell C, Mackenzie M, Reid M, et al. National evaluation of Keep Well. Strategies for reaching the target population. Interim report. Edinburgh: NHS Health Scotland, 2009.

26. Connell JP, Kubisch AC, Schorr LB, Weiss CH. New approaches to evaluating community initiatives: Concepts, methods and contexts. Washington, DC: The Aspen Institute, 1995.

27. Pawson R, Tilley N. Realistic evaluation. London: Sage Publications, 1997.

28. Ritchie J, Spencer L. Qualitative data analysis for applied policy research. In: Bryman A, Burgess RG (eds). Analyzing qualitative data. London: Routledge, 1994: 173-194.

29. Allender S, Scarborough P, Peto V, et al. Chapter 2; Morbidity. In: European cardiovascular disease statistics, 2008. British Heart Foundation http://www.bhf.org.uk/publications/view-publication.aspx?ps=1001443 laccessed 7 Mar 2012)

30. Allender S, Scarborough P, Peto V, . Chapter 1; Mortality. In: European cardiovascular disease statistics, 2008. British Heart Foundation (http://www.bhf.org.uk/publications/view-publication.aspx?ps=1001443) (accessed 7 Mar 2012).

31. Anand SS, Yusuf S. Stemming the global tsunami of cardiovascular disease. Lancet 2011; 377(9765): 529-532.

32. Wang Y, O'Donnell C, Mackenzie M, et al. National evaluation of Keep Well. Keep Well - reach and engagement. Policy \& Practice Paper No 4. Edinburgh: NHS Health Scotland, 2010.

33. Turner F, Mackenzie M, O'Donnell C, et al. National evaluation of Keep Well. Models and impact of outreach in Keep Well. Policy \& Practice Report No 3. Edinburgh: NHS Health Scotland, 2010.

34. Graham $\mathrm{H}$. Social determinants and their unequal distribution: clarifying policy understandings. Milbank Q 2004; 82(1): 101-124.

35. McGregor W, Jabareen H, O'Donnell CA, et al. Impact of the 2004 GMS contract on practice nurses: a qualitative study. $\mathrm{Br} J$ Gen Pract 2008; 58(10): 711-719

36. O'Donnell CA, Jabareen H, Watt GCM. Practice nurses' workload, career intentions and the impact of professional isolation: a cross-sectional survey. BMC Nurs 2010; 9(1): 2.

37. McDonald R, Campbell S, Lester H. Practice nurses and the effects of the new general practitioner contract in the English National Health Service: the extension of a professional project? Soc Sci Med 2009; 68(7): 1206-1212.

38. Department of Health. Putting prevention first. London: Department of Health, 2008.

39. Daniel KL, Bernhardt JM, Eroglu D. Social marketing and health communication: From people to places. Am J Public Health 2009; 99(12): 2120-2122. 